\title{
Estudio Para la Valoración y Recuperación del Patrimonio Arquitectónico Religioso Venezolano a Través de Técnicas Digitales: Iglesia de San Jacinto, Caso de Estudio
}

\author{
Study for Assessment and Recovery of Venezuelan Religious Architectural Heritage Through Digital \\ Techniques: Church of San Jacinto, Case Study
}

\author{
Mariolly Dávila Cordido \\ Universidad Simón Bolívar, Venezuela \\ mariollydavila@usb.ve
}

\begin{abstract}
The purpose of this paper is to implement a methodology for the recovery of religious architectural heritage of Venezuela, exemplified in a case study: the virtual reconstruction of the church of San Jacinto, located in Caracas. The methodology consists of four stages: two investigative, graphic and informative stage using QR codes. As hypothesis is proposed that, given the limited existing documentation, should supplement the study and lifting Venezuelan Canarian churches with altarpieces and, based on that, characterize and play virtually Venezuelan colonial church model.
\end{abstract}

Keywords: Colonial architecture; Religious heritage; Virtual reconstruction; Visual simulation; QR.

\section{Introducción}

Hoy en día el patrimonio arquitectónico religioso venezolano necesita ser preservado urgentemente. Para ello a nivel metodológico se presentan nuevas estrategias.

Este trabajo tiene como objetivo aclarar este proceso a partir de la relación de ciertos valores: espaciales, mobiliarios y tecnológicos, propios de la obra arquitectónica, para plantear, en un caso de estudio con la reconstrucción virtual de la Iglesia de San Jacinto, en Caracas, las pautas metodológicas para la restauración, consolidación, conservación y valoración del patrimonio religioso venezolano. Completado con su particular relación con el mobiliario: los retablos.

La metodología que ha guiado esta reconstrucción, consta de cuatro etapas. La primera ha sido el levantamiento a partir de datos fotográficos y métricos de los retablos, de las plantas y secciones de seis iglesias canarias y venezolanas. La segunda etapa ha sido la del conocimiento a través de la documentación bibliográfica, arqueológica, histórica y urbanística de la cuadra donde se situaba la iglesia de San Jacinto y del propio templo en sí. La tercera fase ha consistido en el modelado virtual del templo con aplicaciones informáticas convencionales. Por último, una cuarta fase de carácter divulgativo del material producido, utilizando la tecnología de los códigos QR, Quick Reference.

Como resultado se ha tipificado, el modelo de iglesia colonial venezolana: una iglesia de planta basilical con tres naves, separadas por seis pilares, de orden toscano, que soportan arcos. La techumbre construida a base de pares y nudillos de estilo mudéjar.

\section{Consideraciones Teóricas y Metodologías del Estudio}

\section{El estado de la cuestión}

La arquitectura colonial en Venezuela está ligada al descubrimiento de América. Su recuperación y revalorización se debe a la labor del historiador y arquitecto italiano Graziano Gasparini. Es a través de su trabajo que se plantea una línea metodológica para la restauración del patrimonio arquitectónico venezolano que se caracteriza por el análisis directo del edificio, a la vez que compensa su falta de documentación bibliográfica.

En 1959, a través de su primer libro: Templos Coloniales en Venezuela, donde pone de manifiesto que había una arquitectura colonial en el territorio venezolano. La metodología empleada fue la de recopilar y registrar fotos, planos, levantamientos y datos de doscientos cuarenta iglesias coloniales. A partir de allí pasó a las casas, a las casas de hacienda, a las fortificaciones, al urbanismo, a la ciudad del siglo XVI y a las influencias que pudieran venir de Europa. Profesor titular de la Facultad de Arquitectura y Urbanismo de la Universidad Central de Venezuela. Fundador y Director del Centro de Investigaciones Históricas y Estéticas. Fundador de la Dirección de Patrimonio Cultural del CONAC. Ha publicado más de 56 libros sobre temas de arquitectura precolombina y colonial, urbanismo y arquitectura popular.

Su metodología de trabajo se basa en la formación de su manera de ser y de reflexionar. Los cuales se ven reflejados en sus criterios de restauración donde impera la idea de mantener su autenticidad. (Gasparini, 2009, p. 15). 
La arquitecta Virginia Vivas realizó la primera investigación sobre la Cuadra de San Jacinto para su declaratoria de "Bien de Interés Cultural" por el Instituto de Patrimonio Cultural en 1998, y comparó documentos planimétricos antiguos, fotográficos y una prospección arqueológica realizada en el Pasaje Linares en 1997.

Fray Antonio Bueno, O.P., director del Instituto de Historia "Fray Andrés Mesanza", se ha dedicado a recuperar toda la información de los archivos dominicos tanto en Venezuela como en España, ha escrito varios trabajos sobre la historia de la iglesia de San Jacinto, y realizó una reconstrucción del retablo mayor del siglo XVIII.

A partir del trabajo de todos ellos y con su autorización se ha profundizado en los mismos, ampliando el número de retablos a documentar, restituyendo su geometría y reajustando la documentación planimétrica, procediendo a la reconstrucción del templo de San Jacinto a su estado en 1865; una labor que combina el procesamiento de imágenes, los gráficos por ordenador, nociones de visión artificial y estrategias de visualización, entendido como un ejemplo de investigación aplicada a la representación gráfica arquitectónica.

\section{Relaciones Canarias-Venezuela}

Las relaciones Canarias-Venezuela en el campo del arte han sido mencionadas por el historiador E. Marco Dorta y D. Angulo, quienes fueron los primeros en señalarlas. En el área de la arquitectura fue G. Gasparini, el que estableció dichas relaciones.

Canarias fue la puerta de entrada de la cultura europea hacia América y viceversa. El laboratorio donde se definieron las bases del modelo de arquitectura religiosa para luego ser implantado en la provincia de Venezuela. "Una formula arquitectónica basada en diferentes orígenes, desde los basilicales cristianos hasta los españoles andaluces del Alfaraje y enriquecida, además con aportes mudéjares y góticos..." (Gasparini, 1995, p. 15).

En esta investigación se ha estudiado el modelo canario utilizado en la construcción de las iglesias en la Provincia de Venezuela desde el siglo XVI hasta el siglo XIX. Para ello se han analizado seis iglesias: tres en Canarias: las iglesias de San Francisco de Asís y Curato, Santo Domingo en las Palmas de Gran Canaria, y la iglesia de la Concepción en San Cristóbal de La Laguna, Tenerife. En Venezuela, en Caracas, con la Catedral, la iglesia de San Francisco y la Iglesia del Dulce Nombre de Jesús (figura1)

Figura 1. Iglesias canarias y venezolanas. Fuente: imágenes, archivo personal de M. Dávila (2011). Planimetría, elaboración propia.

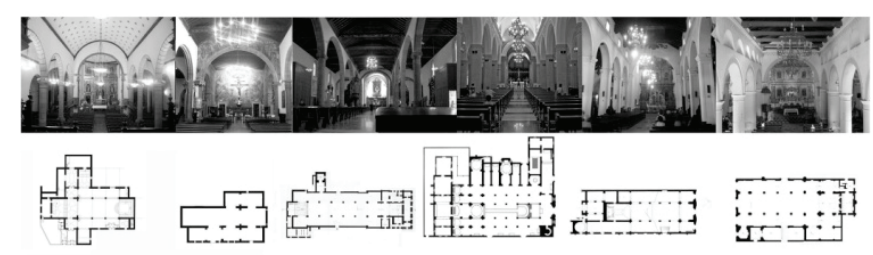

\section{Hipótesis de Partida}

A partir de la poca documentación existente y del estudio y levantamiento de los templos y retablos que se documentan, así como los recogidos en diversas publicaciones, se pudo inferir que existe una manera común de construir específica de Venezuela, influida por Canarias y viceversa, de la que se pudo deducir que la formalización espacial del templo de San Jacinto entronca perfectamente. Para la reconstrucción virtual recurrimos a dos elementos compositivos el espacio documentado a partir de los restos arqueológicos y textos y, en el caso de los retablos, desde los fragmentos que se conservan y de ejemplos similares. Comenzando por las medidas del retablo se deducen las dimensiones de alto y ancho de las naves, y de éstas, a su vez, se infieren las dimensiones de los retablos; el número de calles y de cuerpos. Del retablo mayor deducimos el ancho y el alto de la capilla y de la nave central, corroborados, en el caso de la iglesia de San Jacinto, por los datos arqueológicos. En el caso de los retablos menores, definimos sus dimensiones hipotéticas horizontales utilizando las dimensiones de las capillas laterales. La altura del retablo, y en consecuencia de las naves y capillas que los contenían, es una incógnita, aunque partimos del supuesto que en su definición formal se toman como base ciertas reglas de la perspectiva cónica cuya metodología estaba perfectamente definida en esta época. Hablamos tan sólo de proporciones y de percepción del espacio. Los retablos, sus medidas, estaban diseñados siguiendo en parte estas reglas para adaptarlos visualmente a los espacios que los contenían.

\section{Metodología}

\section{La cuadra de San Jacinto. Fuentes históricas, arqueológicas y urbanísticas}

La arquitecta y antropóloga Virginia Vivas en un estudio que realizó sobre la cuadra de san Jacinto definió cuatro etapas cronológicas identificadas a través de los cambios sucesivos y los usos cualitativos del espacio (Vivas, 1997, p. 100). Estos periodos van desde la fundación del convento en 1595 hasta la demolición del mercado público y la conformación de la actual parcela en 1998; aunque el periodo más interesante para nuestro objetivo es el comprendido desde 1595 hasta 1821, que es el ciclo de existencia de las edificaciones de la iglesia y del convento, desde su fundación hasta la emisión de la primera Ley de Extinción de Conventos.

La fundación urbana de Caracas y de la cuadra de San Jacinto tuvo su inicio entre 1595 y 1597. La orden de los dominicos adquirió, mediante un traspaso privado, un solar en una manzana sureste, ubicado en el plano realizado por el gobernador Juan de Pimentel de Caracas en 1578. 
En 1600 no estaban acabadas las edificaciones. Un seísmo en 1641 provocó destrozos significantes en la iglesia de San Jacinto, tras lo cual la reconstrucción del templo y su convento se iniciaron rápidamente con el acopio de los materiales de las anteriores edificaciones. En 1772 la cuadra recibió la visita del obispo de Caracas, el Ilmo. Mariano Martí. Su descripción refleja la importancia del conjunto y de la iglesia, de la que nos revela con detalle que era de tres naves separadas por pilares que sujetaban arcos de medio punto con techos de pares y nudillos estilo mudéjar (Vivas, 1997, p. 110).

Durante 1809 y 1810 la situación política y de guerra y la declaración formal de la independencia en la Capitanía General de Venezuela generaron una situación económica inestable, que junto al terremoto de 1812, afectaron a la orden dominica, tuvieron que hacer una capilla provisional en la plaza.

Entre 1815 y 1821 se inició un proceso de estancamiento urbano por la inestabilidad política y económica y un declive definitivo en la orden dominica. En 1821 apareció la primera Ley de Extinción de los Conventos Menores de ocho frailes. En 1837 se ordenó la supresión definitiva del convento.

Para corroborar estos datos escritos procedimos a revisar la planimetría superpuesta por V. Vivas, donde señalaba la ubicación de la iglesia de San Jacinto. Su trabajo consistió en sobreponer tres planos: el levantamiento del solar para el momento de su estudio, con los datos aportados por las catas arqueológicas, el plano del ingeniero A. Lutowsky de 1852 y el plano del mercado del arquitecto $\mathrm{H}$. Manrique de 1896 (figura 2). En 1848 se declara a San Jacinto como lugar de emplazamiento para el mercado y en 1851 se prevé su construcción. Se ha podido consultar dos proyectos diferentes para la construcción de este nuevo mercado. La primera propuesta era de A. Lutowsky, la cual nunca se llegó a concretar. El mercado que funcionó en esta zona, y del que hoy en día tenemos fotos, es del proyecto del arquitecto $\mathrm{H}$. Manrique. No obstante, en el plano de Lutowsky de 1852, podemos observar los límites de la iglesia. En él se aprecia como el edificio proyectado se superponía a la plaza, la cruzaba con dos puentes hacia el eje norte-sur demolía todas las construcciones que se encontraban en la parte baja del solar pero respetaba el espacio de la iglesia y del convento. El plano está acotado y las medidas están en varas. La otra propuesta para el mercado fue hecha por el arquitecto $\mathrm{H}$. Manrique en 1896. Su construcción se realizó sobre los mismos cimientos de la iglesia, respetando, su planta y sus principios estructurales.
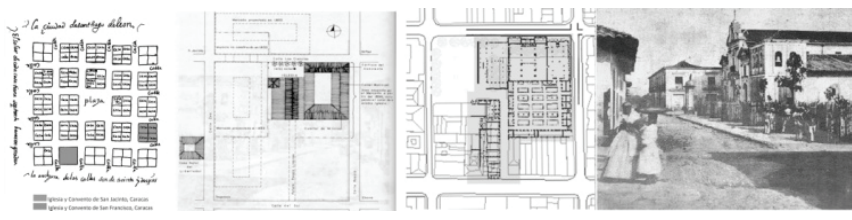

Figura 2: Análisis de la documentación urbanística, arqueológica.

\section{El templo. Investigación de fuentes bibliográficas}

Se sabe por las investigaciones hechas por Fray Antonio Bueno que en el solar de San Jacinto se localizaron cinco tipos de construcciones eclesiásticas durante su existencia. La primera es la de un bohío. La segunda, según Fray Manuel de Santa María, es la de una iglesia de tres naves; la tercera, es la iglesia descrita en la visita de obispo Martí y presentaba la misma fachada y una sola puerta de entrada, además de la nueva nave de la Orden de los Terceros. El cuarto templo provisional referido por Fray Felipe Espinosa es la iglesia y el convento arruinados por el terremoto de 1812. Por último, la quinta construcción eclesiástica es la iglesia del inventario hecho al tiempo de la entrega del templo y supresión del convento (Bueno, 2004, p. 154). En la figura 3 se explica gráficamente los cuatro modelos construidos, resumidos en tres plantas.
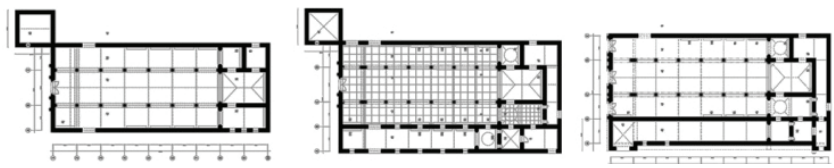

Figura 3: Reconstrucción de las plantas del templo en 1600-1641, 1772 y 1812. Fuente: Planimetría, archivo personal de M. Dávila (2011), elaboración propia.

\section{La investigación sobre los retablos. El Retablo Mayor del siglo XVII.}

Los retablos forman parte sustancial de la configuración de los templos coloniales venezolanos. Centrados en la documentación del templo de San Jacinto nos encontramos que el retablo Mayor del siglo XVII es la única pieza ornamental que se ha conservado parcialmente. Según el trabajo de reconstrucción literario realizado por Fray Antonio Bueno, se sabe que era un retablo en el que hay que señalar dos etapas: la primera etapa plateresca, durante el siglo XVII y primeros años del siglo XVIII y una segunda etapa, en la que se incorporan elementos barrocos que modifican su aspecto original (Bueno, 2004, p. 155). El autor del mismo es desconocido y se sabe que constaba de tres cuerpos al que le cortaron el ático y el pedestal para colocarlo en la iglesia de San Mateo, Edo Aragua. Las dimensiones resultantes serían 9 × 14, 9 varas $(7,50 \mathrm{~m} \times 12,45 \mathrm{~m})$, muy similares a la sección aurea y que de alguna manera corroborarían nuestras hipótesis compositivas.

Del resto de retablos, se sabe por la primera descripción del siglo XVII de las capillas laterales en el informe remitido al Gobernador Berroterán en 1698, que en la capilla del Santísimo Jesús y la capilla de la Virgen del Rosario, ubicadas a cada lado del altar mayor, existían dichos retablos (Bueno, 2004, p. 150).

En base a esas descripciones se ha propuesto los correspondientes retablos respetando las proporciones que tendrían las capillas a partir de los cimientos existentes. 
Análisis gráfico, levantamiento y reconstrucción virtual: Recreación del templo a través del dibujo

Para este artículo nos centraremos exclusivamente en la reconstrucción del templo de 1865. Para ello, además de las comprobaciones hechas por Virginia Vivas, las propuestas de mercado de Lutowsky y Manrique, usaremos la fotografía de Lessmann de 1874 (figura 2).

Todos ellos ubican la iglesia del siglo XIX en el medio de la parcela. Además, para la definición de su volumetría hemos recurrido al estudio de representaciones pictóricas, como un óleo de Nuestra Señora de Caracas del siglo XVII, pintado por la Escuela de los Landaeta, y un grabado: Vista de la ciudad de Caracas, realizado por W. Wood en 1851, en los que hemos podido identificar vistas del templo (figura 4).Con todo ello y tras documentar la evolución de la edificación, damos por sentado que la estructura de la iglesia del siglo XIX se apoyaba en las estructuras de las iglesias del siglo XVII y XVIII. En segundo lugar partimos de la base, por los estudios históricos ya descritos, que nos encontramos frente a un templo de planta basilical con arcos torales y techos mudéjares. En paralelo, hemos procedido a redibujar y reinterpretar los tres templos con sus respectivas plantas, secciones y sus dos alzados; norte y oeste, detalle que se reproduce en la figura 5.

El sistema estructural consta de tres tipologías bien diferenciadas. En un primer conjunto, las tres naves; en un segundo conjunto, la estructura de la cabecera de la iglesia, que comprende las tres capillas principales y en un el tercer conjunto, la sacristía. El primero está conformado por pilares de orden toscano que sujetan los arcos de medio punto y que a su vez separan las naves entre sí. Este número de columnas está descrito por Fray Manuel de Santa María en 1698 (Bueno, 2004, p. 150). También corrobora esta idea el plano del mercado de $\mathrm{H}$. Manrique, en el que se puede apreciar que el número de pilares de la zona donde se encontraba las naves de la iglesia coincide con los seis puntales antes descritos. En el segundo conjunto hay una combinación de muros de cargas y algunos pilares que limitan las capillas con las naves. Estos pilares más elevados que los de las naves, sujetan el sistema de arcos torales. El tercer conjunto de espacios de servicio no sigue el esquema de planta basilical.

Con respecto al sistema de cubierta partimos siempre que la techumbre era de madera con armadura de pares y nudillos. Como dice Gasparini (Dávila, 2010): “Las iglesias cubrieron su capilla mayor con cúpula mampuesta o de madera: las naves centrales, sin excepción, se cubrieron con armadura de par y nudillo y las laterales en colgadizo" Por todo ello asumimos que en esta iglesia la cubierta era similar. Por lo que respecta a los cerramientos: el ladrillo con cal en los muros y las ventanas con vidrieras y hierro eran los materiales utilizados en la construcción de las fachadas.
En el caso del templo del siglo XVIII, se mantiene el mismo concepto. En el cuadro al óleo de Nuestra Señora de Caracas del siglo XVII pintado por la Escuela de los Landaeta (figura 4), se puede observar el aspecto del templo con su espacio libre frente. La iglesia dispuesta en el centro del solar poseía una fachada con una sola puerta que daba a la plaza. Además de ello se le suma una nave más; la nave de los Terceros. Características referenciadas en la visita al templo en 1772 por el Ilmo. Mariano Martí. (Bueno, 2004, p. 151).

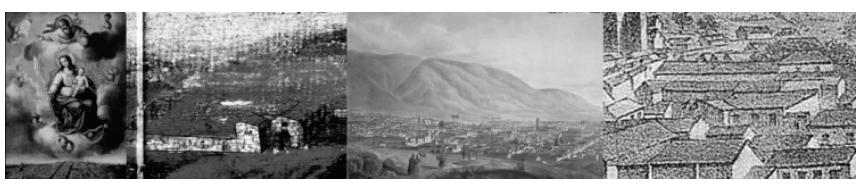
Figura 4:. Estudio de fuentes pictóricas. Fuente: Elaboración propia a partir de las fuentes.

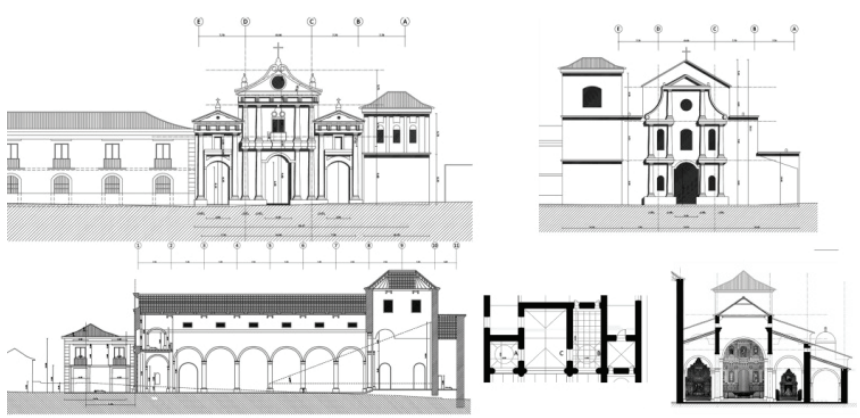

Figura 5: Fachadas, secciones longitudinales y transversales del templo de San Jacinto reconstruido en su aspecto en los siglos XVIII y XIX. Fuente: elaboración propia.

\section{Recreación interior de la iglesia de San Jacinto a través de un modelo virtual 3D}

De estos tres modelos secuenciales de las iglesias estudiadas, se ha seleccionado la segunda como el modelo más desarrollado para el estudio espacial, la iglesia del siglo XVIII, compuesta por el espacio de las tres naves, la capilla de los Terceros, la sacristía, los almacenes y la torre dentro de la estructura del convento. Dicho templo estaba ubicado en el medio del solar y su acceso frontal, desde el espacio público. En nuestro modelo hemos reproducido tanto las vistas estáticas como los recorridos importantes. En este sentido, hay que entender que la configuración de los recorridos está ligada a la jerarquización de los espacios. El de mayor importancia se produce siguiendo la nave central, que es el elemento organizador de espacios. Hay tres recorridos lineales paralelos el de la nave del evangelio, de la epístola y el de la nave de los Terceros que finalizan en la capilla del Dulce Nombre de Jesús y la capilla de Rosario.

El otro aspecto es el de los materiales que eran tres; mampostería cerámica ensamblada con cal en los muros y pilares, madera con artesonados de estilo mudéjar en las techumbres y ladrillo o piedra en el pavimento. (Figura 5) 


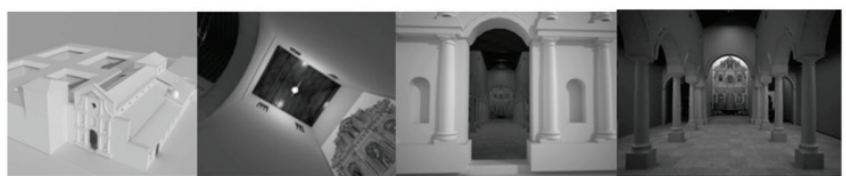

Figura 6: Modelo virtual y vistas interiores y exteriores. Fuente: elaboración propia.

\section{Recreación de los retablos de las naves del evangelio y de la epístola del siglo XVIII}

Para acentuar el realismo de nuestra propuesta se procedido a reconstruir virtualmente los retablos más importantes del templo. Sabemos que existían retablos en la nave del evangelio, en cuya cabecera estaba la capilla del Dulce Nombre de Jesús. En la nave de la epístola se encontraba la capilla de la Virgen del Rosario. Sobre esta base, hemos deducido cual era el aspecto de los mismos $y$, en consecuencia, hemos completado la planimetría del templo en esa zona. De esta manera, en la planta de la iglesia tenemos las capillas del Santísimo Jesús y del Rosario y sabemos que ambas tenían la misma proporción de 6 varas de largo por 30 varas de ancho $(5,0 \times 25,0 \mathrm{~m})$. El largo en la capilla del Rosario era el doble que en la capilla del Santísimo Jesús. Atendiendo a la lógica compositiva del conjunto eclesiástico y a los datos documentados, el retablo de la capilla del Santísimo Jesús y el retablo de la capilla del Rosario deberían ser casi iguales en proporción. El primero pudo haber sido más grande al no tener puertas laterales.

Tendríamos, dos retablos de una sola calle y dos cuerpos, con una base. El retablo de la capilla del Santísimo Jesús debería tener unas 6,30 varas de ancho por 6,75 varas de alto $(5,30 \mathrm{~m} \times 5,65 \mathrm{~m})$. El retablo de la capilla del Rosario sería de unas 3,30 varas de ancho por 6 varas de alto $(2,75 \mathrm{~m} \times 5,0 \mathrm{~m})$, medidas que deducimos de las plantas y secciones elaboradas.

\section{La difusión y consulta mediante códigos QR en Internet}

La propuesta sirvió para generar un código $Q R$, una matriz de puntos bidimensional, que se colocó impreso en el Reloj de Sol de la plaza de San Jacinto. Los teléfonos móviles de última generación con aplicaciones gratuitas de lectura permiten acceder a la información oculta en los códigos a través de su captura con la cámara fotográfica, lo cual nos remite a una conexión a internet donde está depositado el material; en nuestro caso, en Youtube.

\section{Conclusiones}

Este estudio ha servido para poner en práctica una nueva metodología; que parte de una experiencia previa tras el reconocimiento fotográfico y de un levantamiento planimétrico de seis iglesias canarias y venezolanas, la cual se enriqueció con la información bibliográfica, arqueológica, histórica y urbanística y que, por último, se aplicó a la reconstrucción del espacio virtual de la iglesia de San Jacinto, en Caracas. Para propiciar la difusión pública de esta reconstrucción, se plantea la utilización de un sistema de código gráficos $Q R$, que remiten a documentación depositada en la web.

Para generar el modelo de iglesia del siglo XVIII fue necesario el estudio de las diferentes fases de consolidación del templo, desde su fundación hasta 1821 con la Ley de Extinción de Conventos. Se generaron así tres modelos de iglesias, la inicial en el siglo XVII, la del siglo XVIII con la capilla de los Terceros y la de 1874, conocida a partir de la foto de Lessmann. Este modelo virtual ejemplifica el prototipo de iglesia colonial venezolana de tres naves, separadas por pilares que soportan arcos de medio punto y arcos torales con techos de pares y nudillos, lo cual nos ha permitido reconstruir su espacio y sus retablos.

Por todo ello podemos concluir que hemos demostrado como esta metodología fotográfica y de difusión cultural, de fácil acceso y de gran impacto entre el público, como herramienta de recuperación histórica en manos de expertos, nos permite la valoración, protección y conservación del patrimonio arquitectónico religioso de Venezuela. Esta metodología se podría ampliar a otros enclaves y edificios de interés que han desaparecido en Caracas y en el resto del país. De allí su utilidad científica y social, razón que avala esta investigación.

\section{Referencias}

Bueno, Antonio. (2004). Retablos del templo de San Jacinto de Caracas (siglos XVII y XVIII). Separata de Archivo Dominicano, Vol. XXV, Salamanca.

Bueno, Antonio. (1998). El Convento de San Jacinto: Una presencia polifacética. 500 años de Evangelización, Dominicos en Venezuela (1498-1198). Actas del Congreso Internacional de Historia, 15-16 octubre y Caracas 22-23 octubre, Mérida.

Dávila, Mariolly. (2010) Entrevista a Graziano Gasparini. Documento no publicado, agosto 24, 2010.

Gasparini, Graziano. (2009). Escuchar el Monumento. Editorial Arte. Caracas.

Gasparini, Graziano. (1995). La arquitectura de las islas Canarias, 14201788. Armitano Editores, Caracas.

Gasparini, Graziano. (1959). Templos coloniales de Venezuela. Italgráfica, Caracas.

Vivas, Virginia. (1997). Fundamentos para la Declaratoria de Patrimonio Histórico-Cultural del Conjunto Urbano conformado la manzana № 04.01.25 de la Parroquia Catedral de la ciudad de Caracas. Ubicada entre las esquinas de Traposos, El Chorro. Dr. Paúl y San Jacinto Caracas. Fundapatrimonio. Caracas. 